\title{
Análise Germinativa de Sementes Comerciais de Coentro (Coriandrum sativum L.) no município de Serra Talhada - PE
}

\section{Germination analysis Coriander Commercial seed (Coriandrum sativum L.) in Serra Talhada - PE}

\author{
Hamurábi Anizio Lins ${ }^{1 *}$, José Claudio Barros Ferraz ${ }^{2}$, Juliana Alves da costa ${ }^{3}$, Isidro Patrício de Almeida Neto ${ }^{4}$, Thiago Alves \\ Pimenta $^{5}$
}

\begin{abstract}
Resumo: A análise germinativa em sementes de coentro (Coriandrum sativum L.) tem o intuito de avaliar a qualidade fisiológica de sementes para fins de semeadura e comercialização de lotes. Diante disso, a pesquisa teve como objetivo analisar a germinação de sementes comerciais de coentro. O experimento foi conduzido no município de Serra Talhada, PE. Foram utilizadas duas variedades do coentro (Verdão e Portuguesa), sendo empregados dois tratamentos e dez repetições, contendo 30 sementes cada um. A semeadura foi feita em bandejas de isopor contento 200 células, preenchidas com o substrato comercial. Cada semente de coentro foi colocada no centro de cada célula da bandeja, na profundidade de um centímetro, sendo irrigadas diariamente. Adotou-se o Delineamento Inteiramente Casualizado (DIC). Para realizar as avaliações, foi coletada diariamente a quantidade de sementes emergidas. Os parâmetros avaliados foram porcentagem de emergência (PE), tempo médio de emergência (TME) e velocidade média de emergência (VME). Os resultados foram submetidos à análise de variância, com a significância testada através do teste de Tukey, com até $5 \%$ de probabilidade. Verificou-se que a variedade Verdão diferenciou significativamente da variedade Portuguesa, concluindo assim que a porcentagem de emergência das variedades de coentro não condiz com o indicado pelo fabricante.
\end{abstract}

Palavras-chaves: Germinação, Apiaceae, Planta Condimentar, Qualidade.

\begin{abstract}
The germination analysis in coriander seeds (Coriandrum sativum L.) aims to evaluate the physiological quality of seeds for sowing purposes and sale of lots. Therefore, the research aimed to analyze the germination of commercial coriander seeds. The experiment was conducted in the city of Sierra Talhada, PE. They used two varieties of coriander (Palmeiras and Portuguesa), being employed two treatments and ten replications of 30 seeds each. Sowing was done in satisfaction polystyrene trays 200 cells filled with commercial substrate. Each coriander seed was placed in the center of each cell tray at a depth of one centimeter, and irrigated daily. We adopted a completely randomized design (DIC). To undertake the assessments was collected every day the amount of emerged seeds. We evaluated the percentage of emergence (PE), mean emergence time (TME) and average speed emergency (VME). The results were submitted to ANOVA, with the significance tested by the Tukey test, with up to $5 \%$ probability. It was found that the Verdão variety differ significantly from the Portuguese variety, thus concluding that the percentage of emergence of coriander varieties not consistent with the stated by the manufacturer.
\end{abstract}

Key words: Germination, Apiaceae, Spice Plant, Quality.

\footnotetext{
*Autor para correspondência

Recebido para publicação em 20/02/2015; aprovado em 15/04/2015

${ }^{1}$ Engenheiro Agrônomo, UFCG/CCTA, Pombal-PB; Fone: (83) 99815-6100, hamurabi_a_@hotmail.com

${ }^{2}$ Mestrando em Produção Vegetal, UFRPE/UAST, claudioagronomia@gmail.com

${ }^{3}$ Mestranda em Produção Vegetal, UFRPE/UAST, hamurabi_a_@hotmail.com

${ }^{4}$ Mestrando em Sistemas Agroindustriais, UFCG/CCTA, isidroneto2@gmail.com

${ }^{5}$ Aluno de Graduação do Curso de Agronomia da Universidade Federal de Campina Grande (UFCG/CCTA); t.pimenta62@gmail.com
} 


\section{INTRODUÇÃO}

A qualidade de lotes de sementes se destaca a partir da análise do seu potencial fisiológico, que é verificado não somente através do teste de germinação cotidiano usado em laboratórios de análise de sementes, mas principalmente através dos testes de vigor, que detectam diferenças fisiológicas para lotes de mesma percentagem de germinação. A alta qualidade das sementes é um pré-requisito para se obter mudas vigorosas, uniformes e um estande com produtividade e qualidade (COSTA et al, 2008).

Segundo Nascimento et al. (2011), a qualidade fisiológica da semente é motivo de preocupação, recebendo maior atenção do agricultor, por estar diretamente relacionada ao estabelecimento das plântulas em campo, com reflexos diretos no desenvolvimento inicial da lavoura. Uma vez que, as informações contidas nas embalagens comerciais nem sempre correspondem ao que se observa em campo.

$\mathrm{O}$ teste de germinação realizado em sementes comerciais vem sendo criticado, pois frequentemente obtém-se resultados em laboratório que não se relacionam aos da emergência das plântulas em campo, onde as condições ambientes encontradas são adversas, promovendo resultados de emergência de plântulas inferiores aos obtidos nos testes de germinação conduzidos em laboratório (TILLMANN, 2010).

A germinação de sementes necessita de condições adequadas de umidade, aeração, temperatura e luz. O fornecimento de água é condição fundamental para que a semente inicie e desenvolva normalmente o processo de germinação (DIAS et al., 2010).

As sementes são consideradas de alta qualidade quando apresentam rápida germinação, originando uma plântula normal e sadia, livre de contaminações, com todas as estruturas essenciais desenvolvidas (NASCIMENTO et al., 2011).

O coentro (Coriandrum sativum L.) é uma espécie olerícola de ciclo anual e de suma importância para diversas regiões do Brasil (MARQUES \& LORENCETTI, 1999). Esta espécie apresenta uma ampla adaptação mundial, apresentando facilidade de desenvolvimento nas mais variadas condições climática (CUNHA et al, 2011).

As folhas do coentro são a parte da planta mais utilizada na alimentação humana, participando de muitos pratos regionais, especialmente nas regiões Norte e Nordeste. Apesar de ser uma cultura de destaque, poucos estudos vem sendo realizados para verificar a percentagem de germinação de variedades comerciais (FILGUEIRA, 1993).

Problemas relacionados ao baixo vigor de sementes e ao estabelecimento desta cultura, além da presença de doenças são uma constante nesta espécie, e os estudos realizados a esse respeito ainda são escassos (PEREIRA et al., 2005).

Desta forma, o objetivo deste trabalho foi analisar a germinação de sementes comerciais de coentro (variedades Verdão e Portuguesa) em condições ambientais no município de Serra Talhada - PE.

\section{MATERIAL E MÉTODOS}

$\mathrm{O}$ experimento foi realizado entre os meses de julho a agosto de 2014 situado na Unidade Acadêmica de Serra Talhada, Universidade Federal Rural de Pernambuco, município de Serra Talhada, Estado de Pernambuco, localizado na microrregião do Vale do Pajeú ( $7^{\circ} 56^{\prime} 50,4^{\prime \prime} \mathrm{S}$ e $38^{\circ} 23$ '29" O). O clima é classificado como Bsh (quente e seco) segundo Köppen, adaptada ao Brasil (Coelho e Soncin, 1982), apresentando precipitação média anual de $642 \mathrm{~mm}$ e temperatura média anual de $25,2^{\circ} \mathrm{C}$ (EMBRAPA, 2006).

As variedades de coentro utilizadas foram à portuguesa e o verdão, da marca ISLA, possuindo germinação de $94 \%$ e $94 \%$, pureza $99,9 \%$ e $100 \%$, validade 02/2016 e 04/2016, análise 02/2014 e 04/2014, respectivamente, conforme o fabricante.

O substrato utilizado foi Tropstato HA Hortaliças, indicado para produção de mudas de hortaliças. Produto constituído de casca de pinus, vermiculita, corretivos de acidez e nitrato de potássio.

$\mathrm{O}$ delineamento experimental empregado foi delineamento inteiramente casualizado (DIC), com dois tratamentos e dez repetições, contendo 30 sementes cada tratamento. As variedades foram semeadas em bandejas de isopor contento 200 células, preenchidas com o substrato comercial, sendo colocada uma semente de coentro no centro de cada célula da bandeja, na profundidade de um centímetro, e irrigadas diariamente em casa de vegetação, de maneira a manter o substrato sempre úmido. Foi coletada diariamente a quantidade de sementes emergidas.

Foram avaliados ao final do experimento porcentagem de emergência (PE), tempo médio de emergência (TME) e velocidade média de emergência (VME), conforme fórmulas de cálculo adaptadas de Labouriau \& Valadares (1976):

\footnotetext{
- Porcentagem de emergência: $E=(N / A) \times 100$

$\mathrm{E}=$ porcentagem de emergência;

$\mathrm{N}=$ número de sementes emergidas;

$\mathrm{A}=$ número total de sementes colocadas para emergir;
}

\section{- Tempo médio de emergência: $t=(\Sigma n i t i) / \Sigma n i$ \\ $\mathrm{t}$ = tempo médio de incubação; \\ ni = número de sementes emergidas por dia; \\ ti = tempo de incubação (dias);}

\section{- Velocidade média de emergência: $V=1 / t$ \\ $\mathrm{V}=$ velocidade média de emergência; \\ $\mathrm{t}$ = tempo médio de emergência;}

Os resultados foram submetidos à análise de variância, com a significância testada através do teste de Tukey, com até $5 \%$ de probabilidade através do programa estatístico ASSISTAT.

\section{RESULTADOS E DISCUSSÃO}

A partir da realização do experimento foi constatado, através dos dados obtidos, que as variedades verdão e portuguesa apresentaram valores em relação ao percentual de germinação distintos dos indicados pelos fabricantes.

Foi observado que a variedade verdão apresentou os maiores resultados mediante os parâmetros analisados em relação a variedade portuguesa, indicando assim que a variedade verdão apresentou uma melhor adaptação as condições ambientais locais. 
Tabela 1. Determinação da Porcentagem de Emergência (PE), Tempo Médio de Emergência (TME) e Velocidade Média de Emergência (VME) de sementes comerciais de coentro, Serra Talhada - PE, 2014.

\begin{tabular}{cccc}
\hline Variedade & PE $(\%)$ & TME (dias/semente) & VME (sementes/dia) \\
\hline Verdão & $86,66 \mathrm{a}$ & $7,60 \mathrm{a}$ & $0,13 \mathrm{a}$ \\
Portuguesa & $19,00 \mathrm{~b}$ & $12,77 \mathrm{~b}$ & $0,08 \mathrm{~b}$ \\
\hline CV $(\%)$ & 14,42 & 9,94 & 10,19 \\
\hline
\end{tabular}

Médias seguidas por letras distintas diferem entre si pelo teste de Tukey $(\mathrm{P}<0,05)$.

Estudos realizados por Marques \& Lorencetti (1999), avaliando a porcentagem de germinação de sementes de três cultivares de coentro (verdão, portuguesa e nacional), obtiveram resultados semelhantes aos encontrados nesse experimento visto que as variedades testadas por eles também demostraram um poder germinativo, bem abaixo do indicado pelo fabricante.

Aliados a percentagem de emergência, o tempo e a velocidade média de emergência são fundamentais para o

\section{CONCLUSÕES}

Nas condições em que o experimento foi realizado, foi possível concluir que a porcentagem de emergência das variedades de coentro avaliada não condiz com o indicado pelo fabricante. A variedade Verdão apresentou os parâmetros avaliados superiores à variedade Portuguesa. Para tanto, se torna necessária à realização de estudos da viabilidade das plântulas e sua produtividade final.

\section{REFERÊNCIAS BIBLIOGRÁFICAS}

BEZERRA, A.M.E.; CHAVES, F.C.M.; ASSUNÇÃO, M.V. Produtividade e qualidade das sementes de coentro provenientes de diferentes colheitas. Horticultura Brasileira, Brasília, v.13, n.1, p.72, 1994.

COElHO, M. A.; SONCIN, N. B. 1982. Geografia do Brasil. São Paulo: Moderna. p. 368.

COSTA CJ et al. Potencial fisiológico de sementes de brássicas com ênfase no teste de envelhecimento acelerado. Revista Horticultura Brasileira, Brasília, v. 26, n. 2, p.144-148, 2008.

CUNHA, A. P., ROQUE, O. R., AND GASPAR, N. Cultura e utilização das plantas medicinais e aromáticas. Fundação Calouste Gulbenkian: Lisboa. 2011.

DIAS, R. C. S., SOUZA, R. N. C., SOUZA, F. F., BARBOSA, G. S., DAMACENO, L. S. Sistemas de estabelecimento e condução da cultura do coentro, uma vez que, quanto mais rápido ocorrer à germinação das sementes e a imediata emergência das plântulas, menos tempo as mesmas ficarão sob condições adversas, passando pelos estádios iniciais de desenvolvimento de forma mais acelerada (SILVA et al., 2008). Nascimento, et al. (2011), afirma que temperaturas muito baixas ou muito altas poderão alterar tanto a velocidade quanto a porcentagem final de germinação.

produção de melancia. Embrapa Semiárido. ISSN 1807-0027, Versão Eletrônica. 2010.

\section{EMPRESA BRASILEIRA DE PESQUISA} AGROPECUÁRIA - EMBRAPA. Centro Nacional de Pesquisa de solos. Sistema brasileiro de classificação de solos. Brasília, EMBRAPA, 2006.

FILGUEIRA, R.F. Efeito de diferentes níveis de salinidade do solo no comportamento de duas cultivares de coentro (Coriandrum Sativum L.). Mossoró: ESAM, 1993. 46p. (Monografia de Especialização).

MARQUES, F. C.; LORENCETTI, B. L. Avaliação de três cultivares de coentro (Coriandrum sativum $L$.) semeadas em duas épocas. Pesquisa Agropecuária Gaúcha, v.5, n.2, n. 265-270, 1999.

NASCIMENTO, W. M., DIAS, D. C. F. S., SILVA, P. P. da. Qualidade fisiológica da semente e estabelecimento de plantas de hortaliças no campo. XI Curso sobre Tecnologia de Produção de Sementes de Hortaliças. Porto Alegre/RS, 2011.

PEREIRA, R.S; MUNIZ, M.F.B.; NASCIMENTO, W.M. Aspectos relacionados à qualidade de sementes de coentro. Horticultura Brasileira, Brasília, v.23, n.3, 2005.

TILlMANN, M. A. A. Análise de sementes. Universidade Federal de Pelotas (UFPel), 2010. 83p. (UFPel - Curso de Ciência e Tecnologia de Sementes - Modulo 10 Análise

de sementes). 